\title{
IMPLEMENTASI METODE QUANTUM TEACHING TERHADAP PENINGKATAN HASIL BELAJAR MATEMATIKA PADA SISWA SEKOLAH MENENGAH PERTAMA
}

\author{
Tuty Novelindah Purba \\ SMP Negeri 2 Dolok Pardamean, Indonesia \\ tnpurba@gmail.com
}

Received: January 12, 2021

Revised: February 7, 2021

Accepted: February 12, 2021

\begin{abstract}
:
In general, this study was to determine the application of the quantum teaching-learning method with the discussion method in improving mathematics learning outcomes for seventh-grade students of SMP Negeri 2 Dolok Pardamean, Simalungun Regency. This study used experimental research on grade VII students of SMP Negeri 2 Dolok Pardamean, Simalungun Regency. The research was conducted by taking samples from two classes, namely the experimental class (15 students per class) and the control class (15 students per class). The sample categories were taken from two of four parallel categories that were determined randomly (random category samples). The tool used in this study was a testing technique in the form of empirically verified paper questions. Data analysis used the t-test, first testing for normality and homogeneity. Based on the results of data processing, it was known that the application of the quantum teaching-learning model with the discussion method had a significant effect on increasing mathematics learning outcomes obtained.
\end{abstract}

Keywords: mathematics, learning model, discussion method, quantum teaching.

How to Cite: Purba, T. N. (2021). Implementasi Metode Quantum Teaching Terhadap Peningkatan Hasil Belajar Matematika pada Siswa Sekolah Menengah Pertama, 3(1), 45-54. https://doi.org/10.35316/alifmatika.2021.v3i1.45-54

\section{PENDAHULUAN}

Menurut Deporter (Yani, 2017) mengatakan bahwa Quantum Teaching adalah pengubahan belajar yang meriah, dengan segala nuansanya. Pembelajaran Quantum merupakan inovasi dari perubahan bermacam-macam interaksi yang ada didalam dan sekitar momen belajar. Belajar merupakan kegiatan belajar untuk mengembangkan ilmu. Dimana siswa bertanggung jawab penuh atas proses dan hasil yang mereka peroleh dari proses belajar mengajar. Penilaian dilakukan untuk mendapatkan pekerjaan dari seorang siswa dalam proses menjadi anggota. Ada dua perbedaan utama dalam evaluasi pembelajaran: berita, hasil belajar jangka pendek dan hasil belajar jangka panjang (Siahaan et al., 2021).

Menurut Prasetyasni \& Hadi (2012: 2) Pendidikan yang baik tidak hanya mempersiapkan siswa untuk suatu pekerjaan atau posisi, tapi itu juga membantu memecahkan masalah yang dihadapi kehidupan sehari-hari. Pendidikan mempengaruhi kemampuan individu, perilaku dan kehidupan sehari-hari dalam masyarakat. Itulah mengapa pendidikan sangat penting bagi seluruh umat manusia. Matematika sebagai mata pelajaran dalam satuan akademik merupakan

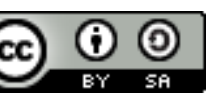
Content from this work may be used under the terms of the Creative Commons AttributionShareAlike 4.0 International License that allows others to share the work with an acknowledgment of the work's authorship and initial publication in this journal. 
mata pelajaran yang tidak mudah oleh siswa. Menurut Rohmayasari (2010: 68) Karakter dan kemampuan berpikir siswa dalam matematika masih sangat lemah dan hasil yang kurang memuaskan, dikarenakan siswa juga merasa bosan dan kesulitan menyelesaikannya.

Jika melihat kembali situasi pembelajaran di Indonesia saat ini dapat dikatakan masih tergolong pembelajaran biasa, karena guru masih berperan dalam menentukan proses pembelajaran, dan siswa hanya berperan sebagai objek pembelajaran dalam praktek di sekolah. Masalah yang dihadapi diantaranya ialah penggunaan metode atau strategi yang kurang akurat dan kurang variatif. Keberhasilan ditentukan tidak hanya oleh model pembelajaran yang diharapkan oleh guru, tetapi pemilihan model pembelajaran dan penerapannya pada proses pembelajaran yang sesuai akan memberikan kontribusi yang besar terhadap komitmen pada proses pembelajaran. Oleh karena itu, perlu adanya perubahan dalam proses belajar mengajar agar siswa tidak sekedar menjadi obyek belajar. Perubahan tersebut dapat dilakukan oleh guru dengan melakukan inovasi dalam proses belajar mengajar yaitu dengan melakukan eksperimen dengan model pembelajaran yang berpusat pada siswa yang diharapkan agar pembelajaran matematika dapat mengembangkan kemampuan berpikir logis, analitis, sistematis, kritis, dan kreatif serta kemampuan bekerja sama. Pelaksanaan pada proses pembelajaran di SMP Negeri 2 Dolok Pardamean, Kabupaten Simalungun siswa hanya mengerjakan tugas atau latihan yang diberikan guru, siswa yang pintar saja yang sering tampil, sedangkan siswa yang lain hanya menyalin jawaban. Walaupun sudah diberi motivasi kepada siswa yang tampil, namun siswa tetap saja tidak mau bekerja mandiri dalam mengerjakan latihan yang di berikan oleh guru. Berdasarkan permasalahan tersebut maka perlu adanya sebuah pembelajaran untuk mengatasinya, pembelajaran yang memiliki kontribusi besar dan diduga mampu mengatasi masalah diatas adalah pembelajaran Quantum Teaching dengan kerangkanya ialah TANDUR yaitu singkatan dari Tumbukan, Alami, Namai, Demonstrasikan, Ulangi, dan Rayakan. Pemilihan Quantum Teaching dikarenakan inti dari pembelajaran ini siswa dapat saling berinteraksi, bekerja sama, mengkontruksi pengetahuan serta dapat meningkatkan hasil belajar matematika.

Sambil mendalami argumen tersebut, sangat utama agar pendidik mengerti kualitas pelajaran, murid dan pendekatan proses pembelajaran ketika memilih model pembelajaran yang baru. Menurut Suryani \& Sari (2014: 39), "The learning model is a model that is applied / chosen by the teacher to provide lessons to students in an integrated manner and align the material to be taught to achieve learning objectives". Artinya model pembelajaran merupakan model yang dilaksanakan / dipilih oleh guru untuk memberikan pelajaran kepada siswa secara teratur dan menyesuaikan materi yang akan mencapai tujuan pembelajaran. Hal ini sesuai dengan pendapat Rusman (2011: 331) yang menyatakan "Dalam pembelajaran kuantum terdapat kerangka yang menjamin siswa menjadi tertarik dan berminat pada setiap mata pelajaran". Dengan demikian, proses pembelajaran akan lebih variatif, inovatif, dan konstruktif dalam membangun wawasan pengetahuan dan implementasinya sehingga dapat meningkatkan motivasi dan kreativitas siswa. Dunia pendidikan adalah dunia yang dinamis dan membutuhkan pembaruan secara terus-menerus (Chatib, 2013: 84). Maka dari itu, lahirlah strategi pembelajaran menarik yang disampaikan oleh Bobby DePorter 
(Darmansyah, 2011: 45) mengatakan bahwa mengembangkan strategi untuk memahami dasar-dasar kurikulum dan efek kurikulum. Quantum Teaching juga menyertakan segala kaitan, interaksi, dan perbedaan yang memaksimalkan momen belajar. Menurut Djamarah (2010: 377) Fun learning adalah pembelajaran yang bertujuan untuk menciptakan suasana yang penuh gairah, kesenangan dan tidak membosankan sama sekali.

Quantum Teaching adalah metode membangun dari Bobby DePorter yang sangat baik untuk para guru. Metode Quantum Teaching merupakan pembelajaran yang menyenangkan dengan segala variasinya dan menciptakan lingkungan belajar yang aktif. Menurut DePorter, Reardon, \& Singer-Nourie (2010: 32), pembelajaran kuantum berfokus pada hubungan antara kehidupan di kelas atau interaksi antara fondasi dan struktur pembelajaran. Selanjutnya, Sultan \& Hajerina (2020) model pembelajaran quantum learning merupakan suatu model pembelajaran yang seluruh proses belajarnya dapat mempertajam pemahaman dan daya ingat, serta membuat belajar sebagai suatu proses yang menyenangkan dan bermanfaat, sehingga pembelajaran menjadi lebih termotivasi. Quantum Teaching erfokus pada hubungan dinamis dalam lingkungan kelas (Abdurrahman, Siregar, \& Umam, 2018; Faj, Fakhri, \& Yusandika, 2018; Ningrum, Lesmono, \& Bachtiar, 2017; DePorter et al., 2010). "Model Pembelajaran Kuantum" Bobby De Porter adalah program yang menguraikan dan belajar melalui proses mendorong dan mempelajari pelajaran yang disampaikan oleh model kepemilikan, sehingga menyederhanakan langkah-langkah baru pembelajaran (Fathurrohman, 2015).

Model Pembelajaran Quantum Teaching dapat ditunjang dengan metode diskusi yang diharapkan agar siswa dapat saling berpendapat, mendengar, dan bekerjasama dalam mempelajari suatu topik tertentu. Diskusi adalah bujukan ilmiah dari beberapa orang yang tergabung dalam suatu kelompok untuk membahas pendapat tentang suatu masalah atau bersama-sama mencari jawaban yang benar. Menurut Stephens (Raheem, 2011: 294), "discussion as a process of giving and speaking, speaking and listening, describing and witnessing which helps broaden horizons and increase mutual understanding. They further explained that only through discussion can one be exposed to new perspectives and exposure to increase understanding and renew motivation to continue learning". Pembelajaran kelas diskusi sangat membantu dalam memahami proses berpikir siswa dalam kaitannya dengan pembelajaran. Pengajaran kelas diskusi dapat mengembangkan pemikiran siswa tentang kemampuan terarah, mendapatkan umpan balik dalam proses pembelajaran, membantu memahami peran siswa di kelas, dan dapat mengembangkan motivasi untuk belajar membantu siswa dalam memahami isi pelajaran, mendorong partisipasi dari partisipasi, dan mendapatkan partisipasi dari partisipasi dan proses berpikir. Berdasarkan pemahaman tersebut, penggunaan diskusi oleh guru berarti memahami apa yang dipikirkan siswa dan bagaimana mengolah ide dan informasi melalui komunikasi yang terjadi selama pembelajaran yang baik antara somnik dan seluruh anggota kurikulum guru dalam komunikasi siswa untuk menganalisis proses berpikirnya. Berdasarkan kerangka berpikir tersebut, diharapkan Quantum Teaching dengan kerangka TANDUR dapat mengatasi masalah yang terkait dengan peningkatan hasil belajar matematika siswa kelas VII SMP Negeri 2 Dolok Pardamean, Kabupaten Simalungun. Penelitian ini bertujuan mengetahui implementasi metode Quantum Teaching menggunakan 
metode diskusi terhadap peningkatan hasil belajar matematika siswa kelas VII SMP Negeri 2 Dolok Pardamean, Kabupaten Simalungun tahun pelajaran $2019 / 2020$.

\section{METODE PENELITIAN}

Penelitian ini menggunakan studi kelompok post-test only randomized dalam desain penelitian ini kelompok eksperimen mendapat perlakuan khusus yang bertujuan meningkatkan kualitas dan kuantitas peningkatan hasil belajar matematika, sedangkan kelompok kontrol tidak mendapat perlakuan khusus, tetapi perlakuannya konvensional, misalnya metode konvensional digunakan dalam pembelajaran yang mana siswa lebih banyak mendengarkan penjelasan guru di depan kelas dan melaksanakan tugas jika guru memberikan latihan soal kepada peserta didik. Rencana percobaan dapat dirumuskan sebagai berikut:

$$
Y_{01} \rightarrow X \rightarrow Y_{11} \rightarrow Y_{02} \rightarrow X r \rightarrow Y_{12}
$$

Keterangan:

$\mathrm{X}=\mathrm{K}$. Kontrol

$X_{r}=$ K. Eksperimen

$Y_{01}=$ Kelas eksperimen sebelum perlakuan

$Y_{02}=\mathrm{K}$. kontrol

$Y_{11}=$ kelas eksperimen sesudah perlakuan

$Y_{12}=$ kelas control

Populasi sasaran dalam penelitian ini adalah murid kelas VII SMP Negeri 2 Dolok Pardamean Kabupaten Simalungun. Sedangkan populasi terjangkau adalah seluruh siswa kelas VII SMP Negeri 2 Dolok Pardamean Kabupaten Simalungun tahun pelajaran 2019/2020 yang berjumlah 143 murid. Sampel penelitian diambil dari populasi sebanyak 30 murid yang terdiri dari 15 murid dari kelas VII - 3 (kelas eksperimen) dan 15 siswa dari kelas VII-2 (kelas kontrol). Teknik pengambilan sampel yang digunakan adalah simple random sampling. Simple random sampling merupakan teknik pengambilan sampel sehingga setiap kasus dalam populasi memiliki peluang bagus untuk dipilih sebagai sampel penelitian.

\section{HASIL PENELITIAN}

\section{Deskripsi Data}

Sebelum penelitian dimulai peneliti telah mengumpulkan hasil ujian tengah semester (UTS) semester ganjil untuk melihat kemampuan awal hasil belajar siswa. Hal ini dilakukan sebagai pedoman untuk mengetahui implementasi metode Quantum Teaching terhadap peningkatan hasil belajar matematika. Hasil belajar dilihat dari hasil tes yang diberikan kepada siswa kelas eksperimen dan kelas kontrol. Hasil analisis hasil belajar pada UTS dapat dilihat pada Tabel 1. 
Tabel 1. Hasil Analisis Ujian Tengah Semester

\begin{tabular}{cccccc}
\hline Kelas & N & Rata-rata & Simpangan Baku & Nilai Min & Nilai Maks \\
\hline Eksperimen & 15 & 58,63 & 16,795 & 35 & 80 \\
Kontrol & 15 & 65,75 & 11,424 & 45 & 78 \\
\hline
\end{tabular}

\section{Analisis Data}

a. Analisis data UTS

Untuk mengetahui kedua kelas sampel memiliki kemampuan awal yang sama maka harus dilakukan uji statistik terhadap skor UTS dengan langkah-langkah sebagai berikut:

1) Uji Normalitas

Uji normalitas menggunakan uji lilefors. Hasil perhitungan uji normalitas skor UTS.

2) Uji Homogenitas

Uji Homogenitas variansi menggunakan uji $\mathrm{F}$, hasil perhitungan uji homogenitas variansi.

b. Analisis Data Post-test

Hasil analisis tes ahkir dapat dilihat pada Tabel 2 dan Tabel 3.

Tabel 2. Hasil Analisis Post-test di kelas eksperimen

\begin{tabular}{ccccc}
\hline Nilai & $\begin{array}{c}\text { Nilai rata- } \\
\text { rata }\end{array}$ & $\begin{array}{c}\text { Nilai } \\
\text { Modus }\end{array}$ & $\begin{array}{c}\text { Nilai } \\
\text { Median }\end{array}$ & $\begin{array}{c}\text { Nilai Simpangan } \\
\text { baku }\end{array}$ \\
\hline $70-98$ & 83,3 & 78,9 & 81,5 & 7,89 \\
\hline
\end{tabular}

Tabel 3. Hasil Analisis Post-test di kelas kontrol

\begin{tabular}{ccccc}
\hline Nilai & Nilai rata-rata & $\begin{array}{c}\text { Nilai } \\
\text { Modus }\end{array}$ & $\begin{array}{c}\text { Nilai } \\
\text { Median }\end{array}$ & $\begin{array}{c}\text { Nilai Simpangan } \\
\text { baku }\end{array}$ \\
\hline $64-93$ & 77,95 & 73,7 & 77 & 7,78 \\
\hline
\end{tabular}

Sebelum menarik kesimpulan, data skor Post-test siswa pada kedua kelas sampel dilakukan analisis secara statistik. Sebelum uji hipotesis, terlebih dahlu dilakukan uji normalitas dan uji homogenitas terhadap skor post-test kedua kelas sampel tersebut.

\section{Uji Normalitas Kelas Eksperimen}

Hasil pengujian nilai kelompok eksperimen $X_{\text {hitung }}=-13,343$, dan dari tabel nilai kritis kriteria chi-kuadrat diperoleh nilai $X_{\text {tabel }}=0,711$ untuk $\mathrm{n}=20$ dengan taraf signifikan $\alpha=0$, 05, karena $X_{\text {hitung }}<X_{\text {tabel }}(-13,343<0,711)$, maka 
$H_{o}$ diterima yang berarti data yang terdapat pada kelas eksperimen berasal dari populasi yang berdistribusi normal. Kemudian populasi dipersingkat secara normal.

\section{Uji Normalitas Kelas Kontrol}

Berdasarkan hasil pengujian untuk kelompok nilai kontrol $X_{\text {hitung }}^{2}=-11,228$ dan dari tabel tersebut diperoleh nilai kritis dari uji chi kuadrat $X_{\text {tabel }}{ }^{2}==0,711$ untuk $\mathrm{n}=20$ pada taraf signifikan $\alpha=0,05$. Karena $X_{\text {hitung }}<X_{\text {tabel }}(-11,228<0,711)$ $H_{o}$ yaitu data yang terdapat pada kelas kontrol dari populasi dengan distribusi normal. maka populasinya dikatakan berdistribusi normal.

\section{Uji Homogenitas}

Hasil perhitungan diperoleh $F_{\text {hitung }}=1,450$ dan $F_{\text {tabel }}=1,729$ pada taraf signifikan $\alpha=0,05$ dengan 19 derajat kebebasan pembilang dan 19 derajat kebebasan penyebut. Karena $F_{\text {hitung }}<F_{\text {tabel }}(1,450<1,729)$, maka $H_{\text {o }}$ dapat dihilangkan pada taraf nyata $\alpha=0,05$. Oleh karena itu dapat diabaikan bahwa kedua data tersebut memiliki varian yang sama (homogen).

\section{Pengujian Hipotesis Penelitian}

Pengujian hipotesis dilakukan dengan kandungan dua rata-rata sesuai dengan hipotesis yang diajukan, sehingga pengujian ini merupakan pengujian rata-rata dua pihak. Untuk menghitung dan hipotesis penelitian, peneliti menggunakan uji-t dengan langkah-langkah sebagai berikut:

Tabel 4. Data Nilai Untuk Uji Hipotesis

\begin{tabular}{ccc}
\hline \multirow{2}{*}{ Kelompok } & \multicolumn{2}{c}{ Nilai hasil belajar siswa kelas XI } \\
\cline { 2 - 3 } & Eksperimen & Kontrol \\
\hline $\mathrm{N}$ & 15 & 15 \\
$\alpha$ & 83,2 & 77,95 \\
$\mathrm{~S}$ & 7,95 & 83,3 \\
\hline
\end{tabular}

Berdasarkan hasil perhitungan interpolasi terlihat nilai t tabel sebesar 1,682, sehingga $t$ hitung $>t$ tabel $(2,09>1,682)$. Dengan demikian, dapat disimpulkan bahwa Ho ditolak atau hasil pengujian memiliki perbedaan yang signifikan. Hal ini menunjukkan bahwa terdapat perbedaan yang signifikan antara rata-rata hasil belajar kubus, balok, prisma vertikal, dan piramida yang diajarkan dengan metode teori kuantum yang menggunakan metode diskusi yang lebih subjektif..

\section{PEMBAHASAN}

Penelitian telah menunjukkan bahwa Metode Diskusi Kuantum dapat meningkatkan hasil belajar kubus, balok, prisma tegak dan limas pada siswa kelas VII-3 SMP Negeri 2 Dolok Pardamean Kabupaten Simalungun semester 2 tahun akademik 2019/2020. Meningkatnya kinerja guru dalam mengajar prisma kubik, 
sudut siku-siku, vertikal, dan piramida melalui penerapan metode Quantum Teaching dengan metode diskusi. Pengajaran guru sudah baik dalam kinerjanya, karena guru dapat memberikan contoh penyelesaian masalah yang berhubungan dengan kehidupan sehari-hari, serta materi yang disampaikan dapat dipahami siswa, soal yang diberikan sudah sesuai dengan indikator keberhasilan dan dalam mengambil kesimpulan sudah mencakup semua materi. Guru dapat menciptakan nuansa belajar siswa lebih aktif, Hal ini karena pembelajaran siswa ikut dilibatkan dan apabila ada siswa yang mengalami kesulitan guru selalu membimbingnya. Selain itu, guru sudah bisa menguasi kelas dengan baik dan juga lebih bisa memotivasi siswa untuk belajar.

Berdasarkan hasil penelitian diperoleh hasil belajar di kelas eksperimen dengan mean 83,3, median 81,5, modus 78,9, simpangan 10,97 dan $X^{2}-13,343$, sedangkan hasil belajar kelas kontrol dengan nilai rata-rata 77 , 95, median 77 , mode 73.3, deviasi 7.28 dan $X^{2}$-1.228. Berdasarkan hasil perhitungan dapat diketahui bahwa nilai rata-rata kelas eksperimen lebih tinggi dari pada kelas kontrol dengan selisih 5,35 dengan data tiap kelas berdistribusi normal dan dari hasil masing-masing. Perhitungan uji homogenitas dapat dilihat $F_{\text {hitung }}, 450$. Oleh karena itu, data kedua memiliki varian yang homogen. Setelah diketahui dari hasil perhitungan bahwa mean eksperimen lebih tinggi dari mean kelas kontrol, maka pengujian menggunakan uji-t yang diketahui diperoleh hasil $t_{\text {hitung }} 2,09$. Dengan demikian dapat diabaikan bahwa $H_{\circ}$ ditolak yang berarti pembelajaran dengan model pembelajaran quantum teaching dengan metode diskusi lebih efektif dibandingkan dengan model pembelajaran konvensional, karena metode Quantum Teaching dengan metode diskusi memiliki kelebihan-kelebihan. Metode Quantum Teaching menciptakan lingkungan belajar yang efesien dan efektif, yaitu dengan cara menggunakan unsur yang ada pada siswa dan lingkungan sekitar belajarnya melalui interaksi didalam kelas (Rumapea, Syahputra, \& Surya, 2017).

Metode Quantum Teaching dengan metode diskusi dapat diterapkan pada materi kubus, balok, prisma tegak dan piramida karena dapat meningkatkan efek belajar, mengembangkan kreativitas siswa dalam materi pembelajaran, dan membantu siswa menemukan dan menolak masalah sistemik, tujuannya agar siswa terinspirasi. Berdasarkan hasil yang diperoleh dari data tersebut dapat diketahui bahwa model pembelajaran kuantum dengan metode diskusi menghasilkan hasil belajar yang lebih tinggi daripada model pembelajaran tradisional, karena model pembelajaran kuantum dengan metode diskusi memiliki kelebihan. Sebagaimana yang diungkapkan oleh Sudjana (Kurniawati \& Taufik, 2015), hasil belajar adalah perubahan kepribadian, dan hasil belajar dapat mencakup bidang kognitif, emosional, dan psikomotorik. Melalui ranah kognitif, peneliti memberikan ujian lisan untuk mengetahui materi, pemahaman konsep dan cara berpikir siswa. Adapun dalam Taksonomi Bloom revisi (Abidin \& Tohir, 2019) menyebutkan ada enam tahapan ranah kognitif yaitu:mengingat (C1), memahami (C2), menerapkan (C3), menganalisis (C4), mengevaluasi (C5), dan mengkreasi (C6). Ranah afektif dilihat dari perilaku siswa dalam berhubungan dengan guru dan sesama siswa selama pembelajaran. Sedangkan ranah psikomotorik dapat dilihat dari keterampilan siswa. Pembelajaran kuantum adalah metode konstruktif, prinsip utamanya adalah membawa mereka ke dunia 
kita dan mentransfer dunia kita ke dunia mereka. Ini sejalan dengan pendapat Sugiyono (2017) mengatakan bahwa dikatakan true eksperimen karena dalam desain ini, peneliti dapat mengontrol semua variabel luar yang mempengaruhi jalannya eksperimen. Maksud dari asas ini menunjukkan bahwa langkah pertama yang harus dilakukan guru di awal proses pembelajaran adalah memasuki dunia siswa dengan mengaitkan mata pelajaran dengan mata pelajaran yang akan dipresentasikan. Setelah guru terbentuk, guru memberikan pemahaman kepada siswa tentang materi yang dipelajari. Dengan demikian, proses pembelajaran akan lebih beragam, inovatif dan konstruktif dalam pembentukan dan pelaksanaan pengetahuan guna meningkatkan motivasi dan kreativitas siswa. Beradasarkan keterangan yang telah dipaparkan, maka dapat disimpulkan bahwa ada pengaruh metode Quantum Teaching dengan metode diskusi terhadap peningkatan hasil belajar matematika pada peserta didik kelas VII SMP Negeri 2 Dolok Pardamean, Kabupaten Simalungun tahun ajaran 2019/2020.

\section{KESIMPULAN DAN SARAN}

Berdasarkan hasil penelitian menunjukkan bahwa pembelajaran matematika menggunakan metode Quantum Teaching dengan metode diskusi menghasilkan peningkatan hasil belajar lebih baik dari pembelajaran matematika menggunakan pembelajaran konvensional. Hal ini dikarenakan pembelajaran matematika, menggunakan kerangka TANDUR membuat peserta didik aktif dalam kegiatan belajar, karena peserta didik dituntut memanfaatkan pengalaman belajar yang telah didapatkanya untuk menemukan kata kunci dan konsep, sehingga akan membuatnya terampil dalam memilih langkah yang dipakai dalam memecahkan masalah misalnya dalam pokok bahasan segita dan analisis, kubus, balok, prisma vertikal, dan piramida diajarkan dengan menggunakan model pembelajaran quantum learning. Artinya implementasi metode Quantum Teaching dengan metode diskusi terhadap peningkatan hasil belajar matematika peserta didik kelas VII SMP Negeri 2 Dolok Pardamean, Kabupaten Simalungun tahun ajaran 2019/2020 terdapat perbedaan antara model pembelajaran kuantum dengan metode diskusi dan model pembelajaran tradisional, yang dapat membuktikan pengaruh model pembelajaran kuantum dengan metode diskusi pembelajaran.

Oleh karena itu, maka sangat di sarankan dalam penyampaian pembelajaran matematika, guru dan calon guru bidang studi matematika perlu memperhatikan adanya penilaian metode pembelajaran yang tepat sesuai dengan materi pokok bahasan yang dipelajari, salah satu alternatifnya metode Quantum Teaching dengan metode diskusi. Ketika melaksanakan kegiatan pembelajaran matematika perlu diperhatikan pentingnya kreativitas belajar matematika dapat tumbuh dan berkembang dari rumah sehingga guru menumbuhkan, mengarahkan dan membimbing siswa agar memiliki kreativitas belajar yang baik. 


\section{DAFTAR PUSTAKA}

Abdurrahman, A., Siregar, A., \& Umam, R. (2018). The effect of feedback as soft scaffolding on ongoing assessment toward the quantum physics concept mastery of the prospective physics teachers. Jurnal Pendidikan IPA Indonesia, $7(1), 41-47$.

Abidin, Z., \& Tohir, M. (2019). Keterampilan Berpikir Tingkat Tinggi dalam Memecahkan Deret Aritmatika Dua Dimensi Berdasarkan Taksonomi Bloom. Alifmatika: Jurnal Pendidikan Dan Pembelajaran Matematika, 1(1), 44-60. https://doi.org/10.35316/alifmatika.2019.v1i1.44-60

Chatib, M. (2013). Sekolahnya manusia: sekolah berbasis multiple intelligences di Indonesia. Kaifa.

Darmansyah, S. (2011). Strategi Pembelajaran Menyenangkan Dengan Humor. Jakarta: PT Bumi Aksara.

DePorter, B., Reardon, M., \& Singer-Nourie, S. (2010). Quantum Teaching: Mempraktikkan Quantum Learning di Ruang-Ruang Kelas. Bandung: PT. Mizan Pustaka.

Djamarah, S. B. (2010). Guru dan Anak Didik Dalam Interaksi Edukatif: suatu pendekatan teoritis psikologis. Jakarta: Rineka Cipta.

Faj, N. A., Fakhri, J., \& Yusandika, A. D. (2018). Efektifitas Model Pembelajaran Quantum Teaching dengan Metode Praktikum terhadap Hasil Belajar Peserta Didik. Indonesian Journal of Science and Mathematics Education, 1(2), 135141.

Fathurrohman, M. (2015). Model-model Pembelajaran Inovatif: Alternatif Desain Pembelajaran yang Menyenangkan. Yogyakarta: ArRuzz Media.

Kurniawati, I., \& Taufik, Y. (2015). The Implementation Of Education Concept 2+ 1 And Estabishing The Professionalism Of Graduates Polytechnic LP3I Bandung. International Conference on Economics and Banking (Iceb-15), 277-282. Atlantis Press.

Ningrum, A. P., Lesmono, A. D., \& Bachtiar, R. W. (2017). Pengembangan Bahan Ajar Berupa Modul Berbasis Quantum Teaching pada Pembelajaran Fisika di SMA. Jurnal Pembelajaran Fisika, 5(4), 315-320.

Prasetyasni, Y., \& Hadi, S. (2012). Perbedaan Penerapan Model Pembelajaran Quantum Teaching dengan Metode Konvensional dalam Hasil Belajar Siswa. Economic Education Analysis Journal, 1(2), 1-6.

Raheem, A. (2011). Effects of Discussion Method on Secondary School Students' Achievement and Retention in Social Studies. Ekiti, Nigeria: University of AdoEkiti. European Journal of Educational Studies 3 (2), Pp: 293-301, Published by Ozean Publication.

Rohmayasari, N. (2010). Pengaruh Pembelajaran Matematika dengan Pendekatan Kontekstual (CTL) terhadap peningkatan Kemampuan Berpikir Analitis dan Kreatif Siswa SMA di Jawa Barat. Skripsi Jurusan Pendidikan Matematika FKIP UNPAS: Tidak Diterbitkan. 
Rumapea, G., Syahputra, E., \& Surya, E. (2017). Application of Quantum Teaching Learning Model to Improve Student Learning Outcomes. International Journal of Novel Research in Education and Learning, 4(2), 118-130.

Rusman. (2011). Model-model pembelajaran: Mengembangkan profesionalisme guru. Jakarta: Rajawali Pers/PT Raja Grafindo Persada.

Siahaan, K. W. A., Lumbangaol, S. T. P., Marbun, J., Nainggolan, A. D., Ritonga, J. M., \& Barus, D. P. (2021). Pengaruh Model Pembelajaran Inkuiri Terbimbing dengan Multi Representasi terhadap Keterampilan Proses Sains dan Penguasaan Konsep IPA. Jurnal Basicedu, 5(1), 195-205.

Sugiyono, S. (2017). Statistika untuk Penelitian (28th editi). Bandung: Alfabeta.

Sultan, L., \& Hajerina, H. (2020). Penerapan Model Pembelajaran Quantum Learning untuk Meningkatkan Hasil Belajar Siswa Kelas VII A MTs. Alkhairaat Biromaru pada Materi Aritmatika Sosial. Guru Tua: Jurnal Pendidikan Dan Pembelajaran, 3(1), 7-20.

Suryani, I., \& Sari, S. A. (2014). Increasing Knowledge Of The Earthquake Preparedness Through Quantum Teaching Model On State Primary School 19 Banda Aceh. The International Journal Of Social Sciences, 19(1), 39-44.

Yani, W. (2017). Pengaruh Metode Pembelajaran Quantum Teaching Terhadap Hasil Belajar Matematika Siswa Kelas VII SMP IT Inayah Ujungbatu. Jurnal Ilmiah Mahasiswa FKIP Prodi Matematika, 2(2), 1-5. 